\title{
Dynorphin- and Enkephalin-like Immunoreactivity is Altered in Limbic-Basal Ganglia Regions of Rat Brain After Repeated Electroconvulsive Shock ${ }^{1}$
}

\author{
T. Kanamatsu, J. F. McGinty, ${ }^{\star}$ C. L. Mitchell, and J. S. Hong \\ Laboratory of Behavioral and Neurological Toxicology, National Institute of Environmental Health Sciences, \\ National Institutes of Health, Research Triangle Park, North Carolina 27709, and \\ *Department of Anatomy, School of Medicine, East Carolina University, Greenville, North Carolina 27834
}

In an attempt to determine whether the opioid peptides derived from prodynorphin participate in the effects of electroconvulsive shock (ECS), we used radioimmunoassay and immunocytochemistry to measure dynorphin-like immunoreactivity (DN-LI) in various rat brain regions after repeated ECS treatments. Ten daily ECSs caused a significant increase in dynorphin A (1-8)LI in most limbic-basal ganglia structures, including hypothalamus $(50 \%)$, striatum (30\%), and septum (30\%). No significant change was found in the frontal cortex or the neurointermediate lobe of the pituitary. In contrast, $10 \mathrm{ECS}$ treatments depleted DN-LI in hippocampal mossy fibers by $64 \%$. A detailed timecourse study revealed that a single shock caused a small but significant increase in hippocampal DN-LI, whereas three consecutive shocks depleted DN-LI by $30 \%$. The maximal decrease in DN-LI was reached after six daily ECSs. The level of DNLI in the hippocampus partly recovered, but remained lower than the control value 4,7 , and $14 \mathrm{~d}$ after the cessation of six daily ECSs (50, 77, and $83 \%$ of control value, respectively). In contrast with the ECS-induced depletion of hippocampal dynorphin, 10 daily ECSs caused a significant increase (40\%) in (Met')-enkephalin-LI in the hippocampus, as well as in other limbic-basal ganglia structures. Immunocytochemistry revealed that enkephalin-LI was increased in the perforant pathway, which is presynaptic to the dynorphin-containing mossy fiber pathway in the hippocampus. These observations suggest that different mechanisms may regulate these two opioid peptide systems in the hippocampus. Moreover, the robust changes of enkephalin and dynorphin in several limbic regions elicited by repeated ECS suggest that these opioid peptides are associated with the behavioral alterations seen in ECS-treated animals.

It has been suggested that endogenous opioid peptides may mediate electroconvulsive shock (ECS)-elicited behavioral alterations, such as analgesia, retrogradc amncsia, changes in seizure threshold, or postictal depression (Carrasco et al., 1982; Holaday and Belenky, 1980; Tortella and Cowan, 1982; Urca et al., 1981, 1983). This notion is supported by our previous report that repeated ECS increases the $\left(\mathrm{Met}^{5}\right)$-enkephalin-like immunoreactivity (ME-LI) of certain limbic areas of the rat brain, such as the septum, amygdala, nucleus accumbens, and hypo-

\footnotetext{
Received Feb. 7, 1985; revised June 10, 1985; accepted June 11, 1985.

We thank Drs. Lars Terenius, Richard Miller, and Eckard Weber for their antisera. Jacqueline Loesche, Kent Slemmons, Johnny Obie, and Billy Scarlett provided excellent technical assistance. The secretarial assistance of Loretta Moore is greatly appreciated.

Correspondence should be addressed to J. S. Hong.

Preliminary results were presented in part at the International Narcotic Research Conference, Cambridge, England, 1984.

Copyright (c) 1986 Society for Neuroscience $0270-6474 / 86 / 030644-06 \$ 02.00 / 0$
}

thalamus, whereas the level of hypothalamic $\beta$-endorphin is unaltered (Hong et al., 1979). Our recent study, using in vitro cell free translation or blot hybridization with a rat preproenkephalin A cDNA clone to estimate the level of mRNA coding for preproenkephalin A, suggested that the increase in hypothalamic ME-LI after repeated ECS is due to an increase in biosynthesis (Yoshikawa et al., 1985). These observations raise the possibility that an increase in enkephalinergic neuronal activity is related to ECS-elicited phenomena.

It was recently reported that the level of hippocampal dynorphin is increased in amygdaloid-kindled rabbits (Przewlocki et al., 1983) and in rats receiving intra-amygdaloid kainic acid (Lason et al., 1983). These observations suggest that, like enkephalin, the metabolic state of dynorphin stored in hippocampal neurons can change in response to seizure activities. In light of these findings, and in an attempt to further examine the possible role of specific dynorphin-containing pathways in relation to convulsions, we determined the regional brain levels of dynorphin A (1-8)-like immunoreactivity (DN-LI) by radioimmunoassay (RIA), and by changes in immunostaining intensity of dynorphin A (1-17)- and dynorphin B-containing neurons, using immunocytochemistry (ICC) after repeated ECS.

\section{Materials and Methods}

\section{Animals}

Male Fischer 344 rats (Charles River, Wilmington, MA) between 10 and 12 weeks of age were used. They were housed, four to a cage, in a colony room with a $12 \mathrm{hr}$ light-dark cycle, and maintained at $21 \pm 2{ }^{\circ} \mathrm{C}$ and $50 \pm 10 \%$ humidity.

\section{Treatment of animals}

ECS was performed daily using a machine manufactured by Biological Research Apparatus (Comecio-Varesa, Italy). The current producing maximal tonic and clonic convulsions was delivered to rats via an earclip electrode with the following parameters: $85 \mathrm{~mA}$ (unless otherwise specified), $50 \mathrm{~Hz}, 1 \mathrm{msec}$ pulse interval for a total duration of $1 \mathrm{sec}$. Sham control rats were treated identically, except that they received 0 $\mathrm{mA}$. With the exception of the study represented in Figure 3, rats were dccapitated for RIA or perfused for ICC (see below) $24 \mathrm{hr}$ after the last shock.

\section{Radioimmunoassay}

Brain regions were dissected according to the method of Glowinski and Iversen (1966). The tissue levels of ME-LI were determined by RIA methods as described previously (Hong et al., 1978). In brief, tissue was homogenized in $2 \mathrm{M}$ acetic acid and immersed in boiling water for 5 min. After centrifuging at $25,000 \times g$ for $20 \mathrm{~min}$, the supernatant fluid was lyophilized. The residue was then reconstituted in RIA buffer solutions and aliquots were used for RIA. The specificity of the antiserum against ME has been described in a previous report (Hong et al., 1978). 
CONTROL
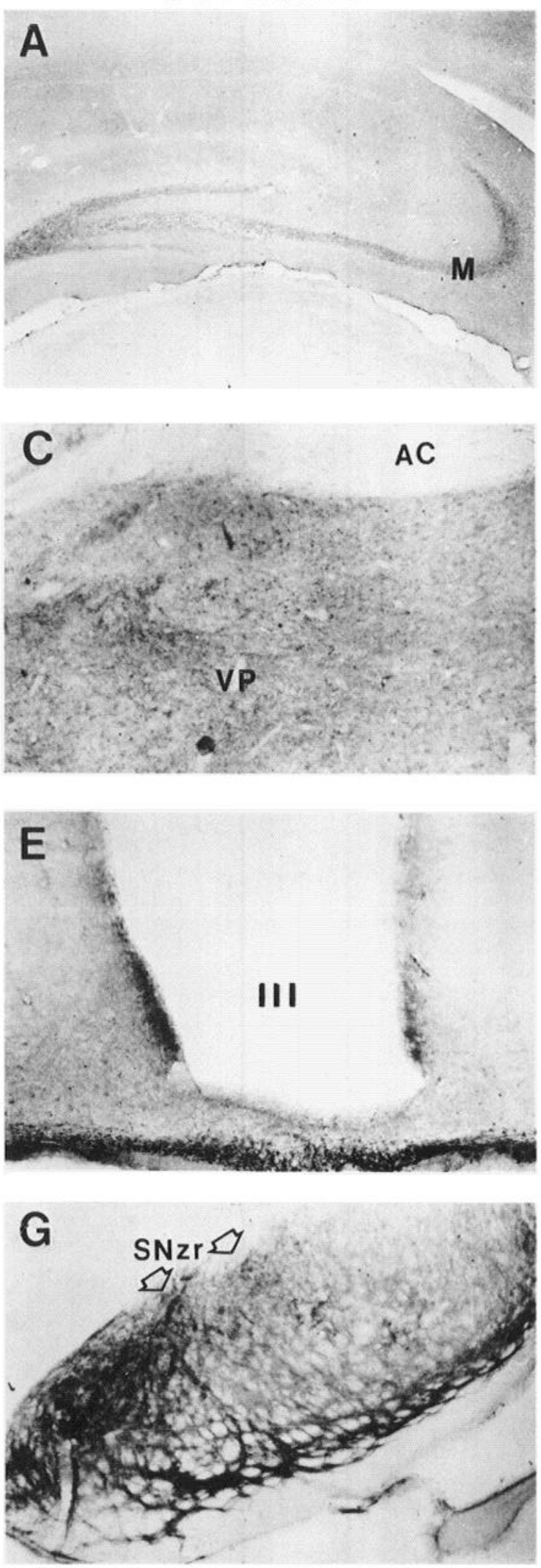

ECS

B
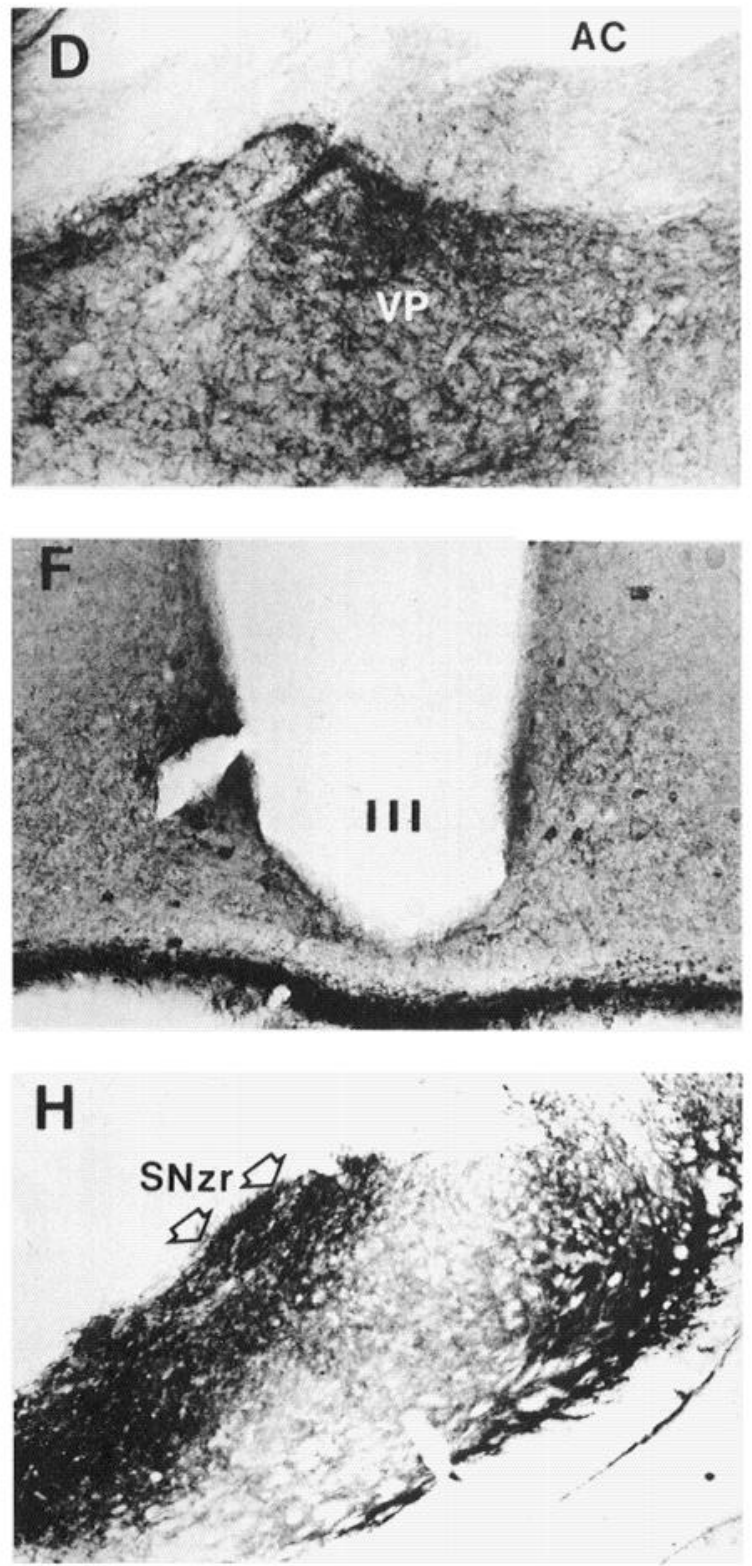

Figure 1. Dynorphin-like immunoreactivity (DN-LI) in coronal sections of limbic and basal ganglia regions $1 \mathrm{~d}$ after six daily ECS treatments (right) or in sham-controls (left). $A$ and $B$, Dynorphin B-LI in hippocampal mossy fibers $(M)$ of the dentate hilus. Repeated ECS virtually eliminated DN-LI in this pathway. $\times 27$. $C$ and $D$, Dynorphin A (1-17)-LI in the ventral pallidum $(V P)$ under the anterior commissure $(A C)$ increased after repeated ECS. $\times 103(C), \times 86(D) . E$ and $F$, Dynorphin B-LI in cells and fibers of the medial basal hypothalamus increased after repeated ECS. $\times 98(E), \times 104(F) . G$ and $H$, Dynorphin A $(1-17)-$ LI in the substantia nigra zona reticulata $(S N z r)$ increased after repeated ECS. $\times 41$. 


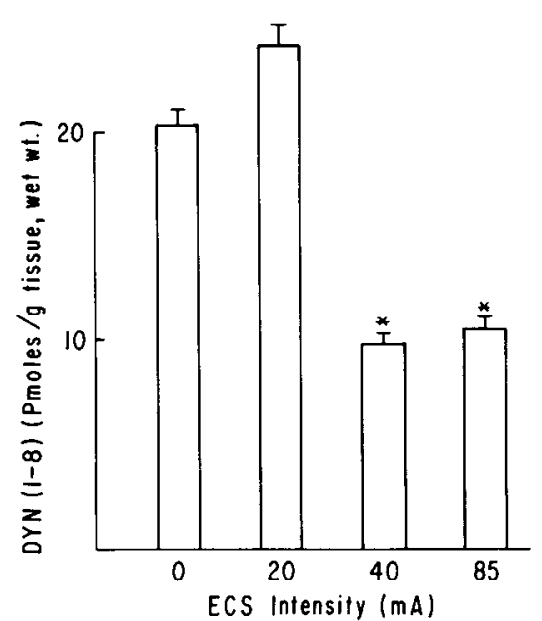

Figure 2. Hippocampal dynorphin (1-8)-like immunoreactivity $1 \mathrm{~d}$ after six daily ECSs with different shock intensities. Each value is the mean \pm SEM of eight rats. ANOVA $(F=20.5, d f=3,28, p<0.001)$. ${ }^{*} p<0.005$, compared to the $0 \mathrm{~mA}$ group.

An antiscrum to dynorphin A (1-8) that docs not cross-rcact with ME or $\left(\mathrm{Leu}^{5}\right)$-enkephalin, but does cross-react somewhat with dynorphin $\mathrm{A}$ (1-13) $(0.02 \%)$ and dynorphin A (1-17) $(0.01 \%)$, was used in RIA for determining the brain level of DN-LI. The detailed procedures for the RIA of dynorphin A (1-8) were identical to those used for $\beta$-endorphin described in a previous report (Hong et al., 1983). In brief, lyophilized tissue extracts were reconstituted in RIA buffer solution $(0.02 \mathrm{M}$ phosphate buffer containing $0.15 \mathrm{~N} \mathrm{NaCl}, 0.01 \%$ (wt/vol) BSA, $0.1 \%$ (wt/ vol) gelatin, and $0.1 \%$ Triton X-100). ${ }^{25} I$-dynorphin $A(1-8)$ was used as a tracer. Free and bound ${ }^{125} I$-dynorphin A (1-8) were separated by charcoal suspension. The sensitivity of this RIA is $\sim 5 \mathrm{fmol}$.

\section{Immunocytochemical method}

Rats were perfused with a $4 \%$ solution of paraformaldehyde, and brains were prepared for ICC as previously described (see McGinty et al., 1983). Three serial $50 \mu \mathrm{m}$ frozen sections were cut at $400 \mu \mathrm{m}$ intervals from the frontal pole through the brain stem. Two out of three adjacent sections in a series were incubated with an antiserum to dynorphin A (1-17) (provided by L. Terenius, Uppsala, Sweden; no detectable crossreactivity to $\alpha$-neoendorphin, (Leu ${ }^{5}$ )- or $\left(\mathrm{Met}^{5}\right)$-enkephalin, $\beta$-endorphin, or dynorphin A (1-8), and $2 \%$ cross-reactivity with dynorphin A (1-13)) or $\left(\mathrm{Leu}^{5}\right)$-enkephalin (LE) (which was provided by R. J. Miller, University of Chicago; no detectable cross-reactivity to $\beta$-endorphin,

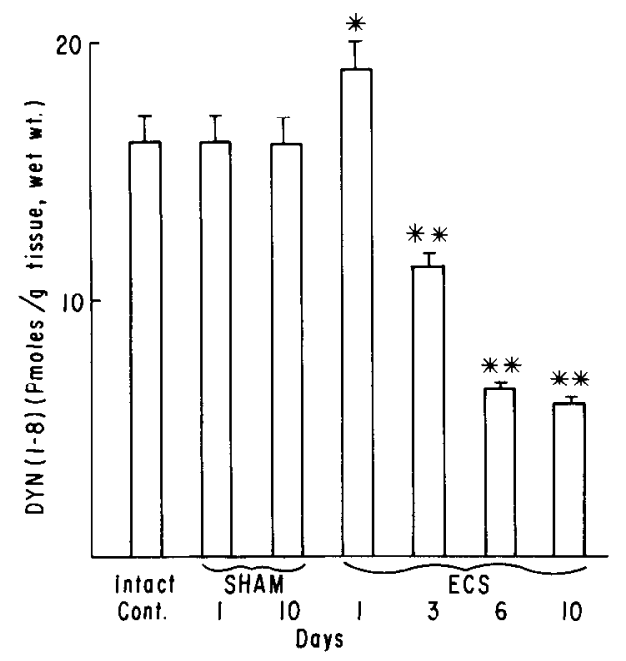

Figure 3. Hippocampal dynorphin A (1-8)-like immunoreactivity 1 $\mathrm{d}$ after $1,3,6$, and 10 daily ECSs. Each value is the mean \pm SEM of eight rats. ANOVA $(F=82.8, d f=6,49, p<0.001) .{ }^{*} p<0.05,{ }^{* *} p<$ 0.01 , compared to sham-control groups.

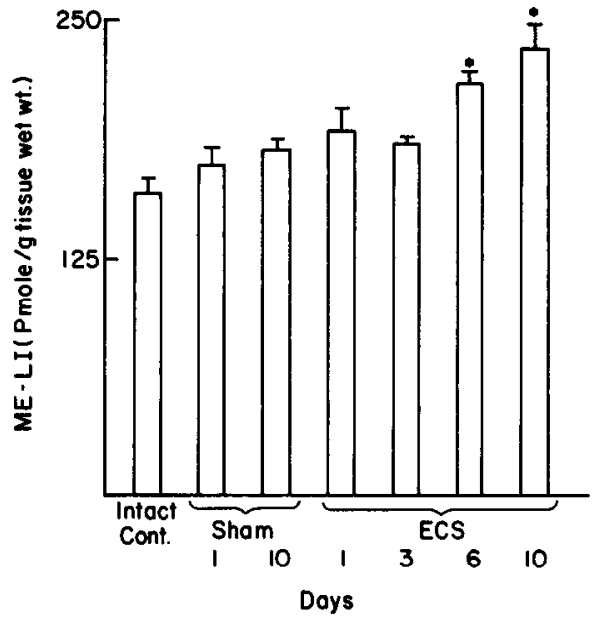

Figure 4. Hippocampal (Met ${ }^{5}$ )-enkephalin-like immunoreactivity $1 \mathrm{~d}$ after $1,3,6$, and 10 consecutive daily ECSs. Each value is the mean \pm SEM of eight rats. ANOVA $(F=6.66, d f=6,49, p<0.005) .{ }^{*} p<$ 0.05 , compared to sham-control groups.

but $10 \%$ cross-reactivity to $\left(\mathrm{Met}^{\mathrm{s}}\right)$-enkephalin), followed by avidinbiotin-peroxidase immunoreagents as described (McGinty et al., 1983). The third section in a series was stained with Richardson's methylene blue-azure II Nissl stain (Richardson et al., 1960). In some experiments, dynorphin B antiserum (provided by E. Weber, Stanford University) or the dynorphin A (1-8) antiserum used in RIA was used instead of the dynorphin $\mathrm{A}(1-17)$ antiserum, or the ( $\left.\mathrm{Met}^{5}\right)$-enkephalin antiserum used in RIA was employed instead of $\left(\mathrm{Leu}^{\mathrm{s}}\right)$-enkephalin antiserum. However, the dynorphin $\mathrm{A}(1-8)$ and $\left(\mathrm{Met}^{5}\right)$-enkephalin antisera were not as good for ICC as they were for RIA.

\section{Statistics}

A one-way analysis of variance (Winer, 1962) was used to test for overall statistical significance: If a significant overall effect of treatment was observed, post hoc comparisons between group means were made using Fisher's least significant difference test (Miller, 1966). Where only two groups were compared (Table 1), a two-tailed Student's $t$ test (Winer, 1962) was used to test for statistical significance. A significance of $p<$ 0.05 was required for rejection of the null hypothesis.

\section{Results}

\section{Dynorphin-like immunoreactivity in various brain} regions after 10 daily ECSs

Ten daily ECSs caused a significant increase in the level of DNLI (1-8) in hypothalamus, septum, striatum, brain stem, and spinal cord, but not in frontal cortex or neurointermediate lobe of the pituitary (Table 1). However, the most conspicuous change in DN-LI (1-8) after ECS occurred in the hippocampus: a $64 \%$ reduction compared with the sham-control group (Table 1). There was a corresponding decrease of dynorphin A (1-17)-like immunoreactivity $(55 \%)$ in the hippocampus of ECS-treated rats (data not shown). In accordance with the RIA data, ICC revealed increased intensity of dynorphin $A(1-17)$ or dynorphin $B$ immunostaining in hypothalamus, dorsal and ventral striatum, ventral pallidum, and substantia nigra (zona reticulata; Fig. 1), as well as of the central nucleus of the amygdala, olfactory tubercle, entopeduncular nucleus, and periaqueductal gray. In the hippocampus, DN-LI in the mossy fibers was virtually depleted (Fig. 1, $A$ and $B$ ) in the absence of any detectable cellular damage (Hong et al., 1985).

\section{Hippocampal DN-LI (1-8) $24 \mathrm{hr}$ after six daily ECSS with} different shock intensities

To determine whether the ECS-induced alteration in hippocampal DN-LI was related directly to the seizure intensity or to a 


\section{CONTROL}
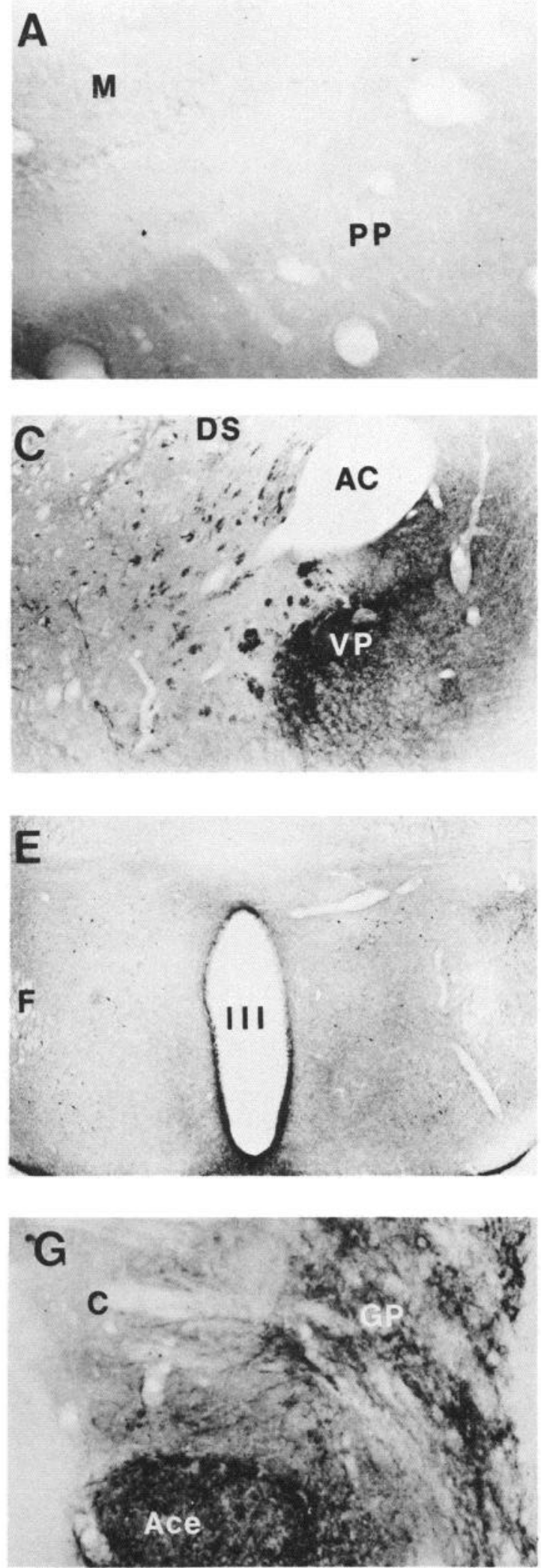

ECS
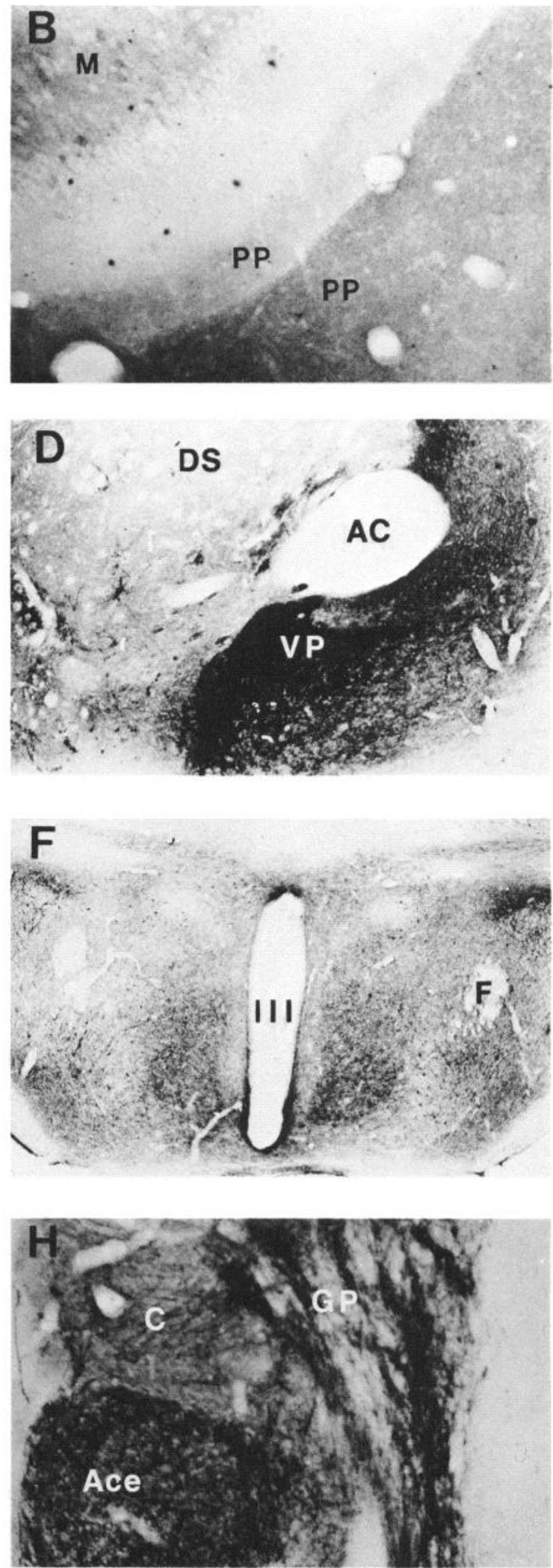

Figure 5. (Leu ${ }^{5}$ )-enkephalin-like immunoreactivity (LE-LI) in coronal sections of limbic and basal ganglia regions $1 \mathrm{~d}$ after six daily ECS treatments $($ right $)$ or in sham-controls $(l e f t)$. $A$ and $B$, LE-LI in the lateral perforant pathway $(P P)$ and mossy fibers $(M)$ of the ventral hippocampus. Repeated ECS increased LE immunostaining, particularly in the perforant path. $\times 100$. $C$ and $D$, LE-LI in the dorsal striatum $(D S)$ and ventral pallidum $(V P)$ is increased by repeated ECS. $A C=$ anterior commissure. $\times 35 . E$ and $F$, LE-LI in the hypothalamus is increased after repeated ECS. $F=$ fornix, $I I I=$ third ventricle. $\times 22 . G$ and $H$, LE-LI in the dorsal striatum, globus pallidus $(G P)$, and central nucleus $(C)$ of the amygdala $(A c e)$ is increased after repeated ECS. $\times 54(G), \times 48(H)$. 


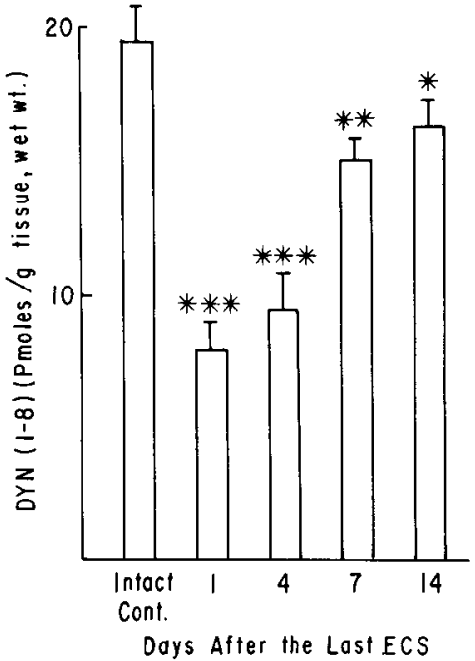

Figure 6. Hippocampal dynorphin A (1-8)-like immunoreactivity at various time periods after the end of six consecutive daily ECSs. Each value is the mean \pm SEM of eight rats. ANOVA $(F=24.1, d f=4,35$, $p<0.001) .{ }^{*} p<0.05,{ }^{* *} p<0.01,{ }^{* * *} p<0.005$, compared to intact control groups.

nonspecific stressful reaction elicited by the shock treatments, various shock intensities were administered to different groups of rats. Six daily shocks of a subconvulsive intensity $(20 \mathrm{~mA})$ failed to alter the hippocampal levels of DN-LI. Repeated ECS with a threshold current of $40 \mathrm{~mA}$, which produced clonic and tonic convulsions, elicited a degree of reduction in the hippocampal DN-LI similar to that produced by shocks with a supramaximal intensity (85 mA) (Fig. 2).

\section{Hippocampal DN-LI (I-8) $24 \mathrm{hr}$ after 1, 3, 6, and} 10 daily $E C S S$

Since repeated ECS exerted a robust decrease in DN-LI in the hippocampus, a detailed study of the time course was performed to determine the minimal number of shocks necessary to induce the maximal depletion. There was a small but significant increase in hippocampal DN-LI $24 \mathrm{hr}$ after a single ECS. However, the level of DN-LI started to decrease (by 30\%) after three consecutive daily ECSs. The maximal reduction $(60-70 \%)$ in the concentration of this opioid peptide was reached after six daily ECSs and did not decrease further after 10 shocks (Fig. 3).
Hippocampal ME-LI $24 \mathrm{hr}$ after 1, 3, 6, and 10 daily ECSs

Previously, we reported that repeated ECS increases ME-LI in several limbic brain regions (Hong et al., 1979). In order to compare the changes in DN-LI with ME-LI in the hippocampus, levels of hippocampal ME-LI from the animals represented in Figure 3 were determined. One or three daily ECSs failed to alter the level of ME-LI. However, there was a significant increase in the levels of this peptide after six and 10 daily ECSs (Fig. 4). ICC revealed that the greatest increase in hippocampal LE-LI or ME-LI occurred in the lateral perforant pathway (Fig. $5, A$ and $B$ ). LE-LI or ME-LI in the mossy fibers was not depleted but showed less consistent increases than had occurred in the perforant pathway. In all other limbic and basal ganglia regions examined, ME-LI or LE-LI was increased. These structures included the dorsal and ventral striatum, ventral pallidum, hypothalamus, and amygdala (Fig. 5, $\mathrm{C}-\mathrm{H}$ ).

\section{Hippocampal $D N-L I$ at various time periods after the completion of six consecutive daily ECSs}

To dctermine whether the level of hippocampal DN-LI, after repeated ECS, recovered over time, DN-LI was measured at 1 , 4,7 , and $14 \mathrm{~d}$ after the completion of six consecutive daily shocks. Four days after the shock treatments, the level of DNLI remained approximately the same as after $1 \mathrm{~d}$ of ECS. There was a significant recovery of the lcvel of DN-LI after 7 d ( $77 \%$ of the control). However, by day 14, DN-LI was still lower than the control value ( $83 \%$ of control; Fig. 6). Immunostaining of DN-LI, LE-LI, or ME-LI in all brain regions of ECS-treated rats did not differ from that in control brains $7 \mathrm{~d}$ after the cessation of treatments (data not shown).

\section{Discussion}

This study demonstrates that the metabolic activity of brain dynorphin-containing neurons, like the activity of enkephalincontaining neurons (Hong et al., 1979), changes in response to the seizure activity induced by repeated ECS. The opioid neurons that respond to ECS-induced seizure activity appear to be contained largely within limbic-basal ganglia structures that are highly interconnected (Nauta, 1979). Changes in opioid peptide metabolism in limbic and basal ganglia pathways subsequent to ECS may reflect primary involvement in ictal and/or postictal events or secondary involvement in ECS-induced analgesia, catalepsy, hyperthermia, respiratory depression, or mental confusion (Carrasco et al., 1982; Holaday and Belenky, 1980; Tortella and Cowan, 1982; Urca et al., 1981).

The most dramatic change in opioid levels after repeated ECS

Table 1. Dynorphin (1-8)-like immunoreactivity of various rat brain regions after 10 daily ECSs

\begin{tabular}{|c|c|c|c|}
\hline \multirow[b]{2}{*}{ Brain region } & \multicolumn{2}{|c|}{$\begin{array}{l}\text { Dynorphin (1-8)-like immunore- } \\
\text { activity (pmol/gm tissue wt } \pm \text { SEM) }\end{array}$} & \multirow{2}{*}{$\begin{array}{l}\text { Percent of } \\
\text { control }\end{array}$} \\
\hline & Sham-control & ECS & \\
\hline Hippocampus & $16.5 \pm 0.6$ & $5.9 \pm 0.2^{* * *}$ & 36 \\
\hline Hypothalamus & $29.4 \pm 1.1$ & $42.7 \pm 1.6^{* * *}$ & 145 \\
\hline Septum & $11.5+0.8$ & $15.0 \pm 0.9 * *$ & 130 \\
\hline Striatum & $55.2 \pm 1.7$ & $70.1 \pm 0.2^{* * *}$ & 127 \\
\hline Medulla oblongata and pons & $14.9 \pm 0.5$ & $17.1 \pm 0.5^{* *}$ & 115 \\
\hline Spinal cord & $5.8 \pm 0.2$ & $6.7 \pm 0.4^{*}$ & 115 \\
\hline Frontal cortex & $4.2 \pm 0.3$ & $4.7 \pm 0.5$ & 111 \\
\hline Pituitary (neurointermediate lobe) & $2.9 \pm 0.2^{a}$ & $2.6 \pm 0.2^{a}$ & 90 \\
\hline
\end{tabular}

Each value is the mean \pm SEM of $7-10$ rats.

${ }^{*} p<0.05,{ }^{* *} p<0.01,{ }^{* * *} p<0.001$.

${ }^{a} \mathrm{pmol} / \mathrm{lobe}$ 
occurred in hippocampal mossy fibers, in which DN-LI decreased by $70 \%$. In the perforant pathway, which is presynaptic to dentate granule cells and their axons (the mossy fibers), LELI/ME-LI increased significantly. The perforant and mossy fiber pathways are the first two links in a trisynaptic excitatory chain through the hippocampal formation. The opposite effects that are exerted by ECS on the concentration of enkephalin and dynorphin peptides in these two pathways suggest that different mechanisms are operative in regulating their metabolism in the hippocampus subsequent to seizure activity. In fact, physiological actions of enkephalins and dynorphins in the hippocampus may be quite different. For example, exogenously administered enkephalins (and morphine) are uniquely excitatory in the hippocampus (Nicoll et al., 1977), where they display potent convulsant or anticonvulsant actions, depending on the circumstances (Frenk, 1983). In contrast, dynorphin does not exert convulsant effects and is less consistently excitatory in the hippocampus (Henriksen et al., 1982).

The mechanism underlying the decrease of hippocampal DN$\mathrm{LI}$ is not clear. Since it is possible that dentate granule cells are susceptible to insults from seizure activities, we considered the possibility that the reduction in DN-LI in the mossy fibers resulted from degeneration of the dentate granule cells. However, light-microscopic histological evaluation indicated that the dentate granule cells appeared to be intact after six daily ECSs (Hong et al., 1985). Furthermore, the time-course study showed a gradual, although partial, recovery of DN-LI in the hippocampus within 2 weeks after the cessation of ECS (Fig. 6). These observations demonstrate that the decrease of hippocampal DNLI after repeated ECS is not due to degeneration of the dentate granule cells. Alternatively, the reduction of DN-LI may be due, either to a reduction in biosynthesis, or to an increase in release. We are currently developing a blot hybridization method, using cDNA coding for prodynorphin, for quantitating the level of prodynorphin mRNA as an index for the biosynthesis of this peptide.

Proenkephalin-derived peptides are present both in the perforant path and, to a lesser extent, in mossy fibers (Gall et al., 1981; McGinty et al., 1983). The enkephalin-like immunoreactivity in the perforant pathway after repeated ECS was consistently enhanced, whereas the enkephalin-like immunoreactivity in the mossy fiber pathway was less obviously and less consistently increased. This observation leaves open the possibility that repeated ECS may also alter the metabolism of enkephalin differently in these two pathways. The mechanism underlying the increase in hippocampal ME-LI is not known at present. However, in view of the reported increase in the level of mRNA coding for proenkephalin in the hypothalamus after repeated ECS (Yoshikawa et al., 1985), it is likely that the ECS-elicited increase in hippocampal ME-LI is due to an increase in the biosynthesis of this peptide. Experiments are currently being conducted to examine this possibility.

This study, and our previous reports (Hong et al., 1979, 1985; Yoshikawa et al., 1985), provide neurochemical evidence that the metabolism of opioid peptides derived from prodynorphin and proenkephalin changes in response to repeated ECS. To our knowledge, this is the first observation that the same metabolic perturbation can differentially alter the concentration of peptides derived from these two opioid families. This differential effect was unique to the hippocampus; in all other affected regions of the brain, seizure activity led to increased levels of both opioid peptide families. The disparity in the seizure-induced changes in ME-LI and DN-LI in the hippocampus may provide an important clue for further understanding the roles of these opioid peptides in relation to seizure-elicited behavioral alterations, such as change in the seizure threshold or loss of memory (Carrasco et al., 1982; Tortella and Cowan, 1982).

\section{References}

Carrasco, M. A., R. D. Dias, and I. Izquierdo (1982) Naloxone reverses retrograde amnesia induced by electroconvulsive shock. Behav. Neural Biol. 34: 352-357.

Frenk, H. (1983) Pro- and anticonvulsant actions of morphine and the endogenous opioids: Involvement and interactions of multiple opiate and non-opiate systems. Brain Res. Rev. 6: 197-210.

Gall, C., N. Brecha, H. J. Karten, and K. J. Chang (1981) Localization of enkephalin-like immunoreactivity to identified axonal and neuronal populations of the rat hippocampus. J. Comp. Neurol. 198: $335-350$.

Glowinski, J., and L. L. Iversen (1966) Regional studies of catecholamines in the rat brain. I. The disposition of ${ }^{3} \mathrm{H}$-norepinephrine, ${ }^{3} \mathrm{H}$ dopamine, and ${ }^{3} \mathrm{H}-\mathrm{DOPA}$ in various regions of the brain. J. Neurochem. 13: 655-669.

Henriksen, S. J., G. Chouvet, J. F. McGinty, and F. E. Bloom (1982) Opioid peptides in the hippocampus: Anatomical and physiological considerations. Ann. NY Acad. Sci. 398: 207-220.

Holaday, J. W., and G. L. Belenky (1980) Opiate-like effects of electroconvulsive shock in rats: A differential effect of naloxone on nociceptive measures. Life Sci. 27: 1929-1938.

Hong, J. S., H.-Y. T. Yang, W. Fratta, and E. Costa (1978) Rat striatal (Met ${ }^{5}$ )-enkephalin content after chronic treatment with cataleptogenic and non-cataleptogenic antischizophrenic drugs. J. Pharmacol. Exp. Ther. 205: 141-147.

Hong, J. S., J. C. Gillin, H. Y. T. Yang, and E. Costa (1979) Repeated electroconvulsive shocks and the brain content of enkephalins. Brain Res. 177: 273-278.

Hong, J. S., K. Yoshikawa, and R. W. Hendren (1983) Measurement of $\beta$-endorphin and enkephalins in biological tissues and fluids. In Methods in Enzymology, Vol. 103, M. Conn, ed., pp. 547-564, Academic, New York.

Hong, J. S., K. Yoshikawa, T. Kanamatsu, J. F. McGinty, C. L. Mitchell, and S. L. Sabol (1985) Repeated electroconvulsive shocks alter the biosynthesis of enkephalin and concentration of dynorphin in the rat brain. Neuropeptides 5: 557-560.

Lason, W., B. Przewlocka, L. Stala, and R. Przewlocki (1983) Changes in hippocampal immunoreactive dynorphin and neoendorphin content following intra-amygdalar kainic acid-induced seizures. Neuropeptides 3: 399-404.

McGinty, J., S. Henriksen, A. Goldstein, L. Terenius, and F. Bloom (1983) Dynorphin is contained within hippocampal mossy fibers: Immunochemical alterations after kainic acid administration and colchicine-induced neurotoxicity. Proc. Natl. Acad. Sci. USA 80: 589 593.

Miller, R. G. (1966) Simultaneous Statistical Inference, McGraw-Hill, New York.

Nauta, H. J. W. (1979) A proposed conceptual reorganization of the basal ganglia and telencephalon. Neuroscience 4: 1875-1881.

Nicoll, R., G. Siggins, N. Ling, F. Bloom, and R. Guillemin (1977) Neuronal actions of endorphins and enkephalins among brain regions: A comparative microiontophoretic study. Proc. Natl. Acad. Sci. USA 74: $2584-2588$.

Przewlocki, R., W. Lason, R. Stach, and D. Kacz (1983) Opioid peptides, particularly dynorphin, after amygdaloid-kindled seizures. Reg. Peptides 6: 385-392.

Richardson, K. D., L. Jarret, and E. H. Finke (1960) Embedding in epoxy resins for ultrathin sectioning in electron microscopy. Stain Technol. 35: 313-323.

Tortella, F. C., and A. Cowan (1982) EEG, EMG and behavioral evidence for the involvement of endorphin systems in postictal events after electroconvulsive shock in rats. Life Sci. 31: 881-888.

Urca, G., J. Yitzhaki, and H. Frenk (1981) Different opioid systems may participate in post electroconvulsive shock (ECS) analgesia and catalepsy. Brain Res. 219: 385-396.

Urca, G., A. Nof, B. A. Weissman, and Y. Sarne (1983) Analgesia induced by electroconvulsive shock: Brain enkephalins may mediate tolerance but not the induction of analgesia. Brain Res. 260: 271277.

Winer, B. J. (1962) Statistical Principles in Experimental Design. McGraw-Hill, New York.

Yoshikawa, K., J. S. Hong, and S. L. Sabol (1985) Electroconvulsive shock increases preproenkephalin messenger RNA abundance in rat hypothalamus. Proc. Natl. Acad. Sci. USA 82: 389-593. 